\title{
Thermal Performance of Various Multilayer Insulation Systems Below 80K
}

\author{
W. Boroski, T. Nicol and C. Schoo \\ Fermi National Accelerator Laboratory \\ P.O. Box 500, Batavia, Illinois 6051 ?
}

April 1992

Presented at the Fourth Annual IISSC Conference, New Orleans, LA, March 4-6, 1992. 


\section{Disclaimer}

This report was prepared as an account of work sponsored by an agency of the United States Government. Neither the United States Government nor any agency thereof, nor any of their employees, makes any warranty, express or implied, or assumes any legal liability or responsibility for the accuracy, completeness, or usefulness of any information, apparatus,

a product, or process disclosed, or represents that its use would not infringe privately owned rights. Reference herein to any specific commercial product, process, or service by trade name, tradem . $^{2}$ manufacturer, or otherwise, does not necessarily constitute or imply its endorsement, recommendation, or favoring by the United States Government or any agency thereof. The views and opinions of authors expressed herein do not necessarily state or reflect those of the United States Government or any agency thereof. 


\title{
THERMAL PERFORMANCE OF VARIOUS MULTILAYER
}

\section{INSULATION SYSTEMS BELOW 80K}

\author{
W.N. Boroski, T.H. Nicol, and C.J. Schoo \\ Fermi National Accelerator Laboratory \\ P.O. Box 500 \\ Batavia, Illinois 60510 USA
}

\section{INTRODUCTION}

The SSC collider dipole cryostat consists of a vacuum shell operating at room temperature, two thermal shields operating near $80 \mathrm{~K}$ and $20 \mathrm{~K}$ respectively, and the superconducting magnet assembly operating near $4 \mathrm{~K}^{1}$. The cryostat design incorporates multilayer insulation (MLI) blankets to limit radiant heat transfer into the $80 \mathrm{~K}$ and $20 \mathrm{~K}$ thermal shields. Also, an MLI blanket is used to impede heat transfer through residual gas conduction into the $4 \mathrm{~K}$ superconducting magnet assembly.

A measurement facility at Fermilab has been used to experimentally optimize the thermal insulation system for the dipole cryostat. Previous thermal measurements have been used to define the $80 \mathrm{~K}$ MLI system configuration and verify system performance 2 . With the 80K MLI system defined, the current effort has focused on experimentally defining the optimum insulation scheme for the $20 \mathrm{~K}$ thermal shield. The SSC design specification requires that radiant heat transfer be limited to $0.093 \mathrm{~W} / \mathrm{m}^{2}$ at an insulating vacuum of $10^{-6}$ torr.

The radiant heat transfer budget to $20 \mathrm{~K}$ can be met without MLI at insulating vacuums of approximately $10^{-6}$ torr. Research indicates that very low heat transfer rates can be achieved between two low emissivity surfaces in the temperature regime below $80 \mathrm{~K}$, provided the insulating vacuum is significantly less than $10^{-6}$ torr. $^{3}$ However, this temperature region is very sensitive to residual gas conduction, with small pressure increases causing significant increases in total heat transfer. Under ideal laboratory or controlled conditions, low insulating vacuum levels are reasonably achieved and maintained. In contrast, insulating vacuums in large accelerators vary

\footnotetext{
- Operated by Universities Research Association, Inc. under contract with the United States Department of Energy
} 
significantly over time. For the SSC cryostat, variations in insulating vacuum will cause oscillations in refrigeration heat loads. Thus, an important advantage of installing MLI on the $20 \mathrm{~K}$ shield of the SSC cryostat is that the reflective layers serve as gas conduction barriers as well as radiation shields. These barriers will buffer the effects of transient conditions on the accelerator refrigeration system.

The performance of several MLI configurations has been evaluated under nominal and degraded insulating vacuum. For each system configuration, the warm boundary temperature remained fixed near $80 \mathrm{~K}$ while the cold boundary temperature was varied from $10 \mathrm{~K}$ to $50 \mathrm{~K}$. Since the SSC dipole cryostat employs aluminum thermal shields, all experimental arrangements included aluminum tape on the warm and cold boundaries. Heat transfer measurements were made with no MLI installed on the cold boundary, and then with 10 and 5-layer MLI blankets on the cold surface. Additionally, the eifect of aluminum coating thickness on MLI performance was studied by measuring the performance of systems with different aluminum coating thicknesses.

\section{EXPERIMENTAL SETUP}

Thermal measurements were made in the Heat Leak Test Facility (HLTF) illustrated in Figure 1. The HLTF as configured for $20 \mathrm{~K}$ MLI measurements has been previously described in detail, and thus only a brief overview is presented here. ${ }^{4}$ Test samples are installed around the cold plate, a cylindrical copper drum with an outer surface area of $0.36 \mathrm{~m}^{2}$. The cold plate outer surface is covered with aluminum tape to simulate the aluminum shield of the cryostat. MLI test samples are installed as blankets around the cylindrical portion of the cold plate and as discs on the bottom section facing the $80 \mathrm{~K}$ thermal shield. Blanket and disc layers are interleaved and taped to minimize the impact of the joint configuration. The cold plate is cooled by solid conduction through a heat flow meter. Heat flow meter accuracy is $\pm 1 \mathrm{~mW}$ near $20 \mathrm{~K}$, which corresponds to a heat flux of $\pm 2.8 \mathrm{~mW} / \mathrm{m}^{2}$ given the cold plate surface area. The heat flow meter is attached to the anchor plate, which establishes the cold boundary temperature. Anchor plate temperature variation is achieved by varying the flow rate of cooling gas through tubing soldered to the cylindrical inner surface. A temperature controller is used to balance electrical power against this flow to maintain a constant temperature. Using the temperature controller and vent gas from 500 -liter liquid helium dewars, constant temperatures over the range $10 \mathrm{~K}$ to $50 \mathrm{~K}$ are achieved.

Encompassing the test sample is a copper shield operating near $80 \mathrm{~K}$. The inner surface area of the $80 \mathrm{~K}$ shield is approximately $0.68 \mathrm{~m}^{2}$, with a radial distance of approximately $5 \mathrm{~cm}$ between the $80 \mathrm{~K}$ shield and the cold plate. The $80 \mathrm{~K}$ thermal shield is cooled through a bolted connection to the bottom of an $\mathrm{LN}_{2}$ reservoir. The inner surface of the $80 \mathrm{~K}$ shield is covered with aluminum tape to simulate the inner surface of the cryostat aluminum $80 \mathrm{~K}$ shield.

System pressure in the HLTF is measured with two Bayard-Alpert ionization gauges. Historically, the lowest insulating vacuums achieved in the HLTF were on the order of $6 \times 10^{-6}$ torr. This level of vacuum had been acceptable for past measurements on $80 \mathrm{~K}$ MLI systems and cryostat mechanical support structures. However, it became clear early in the $20 \mathrm{~K}$ MLI measurement program that insulating vacuum on the order of $10^{-7}$ torr would be necessary to reduce residual gas contribution to negligible levels. Consequently, modifications were made to the vacuum system during the course of the program: the pumping system was reconfigured and the vacuum port size enlarged for increased throughput. This explains why some of the data presented is over broader pressure ranges than others. 


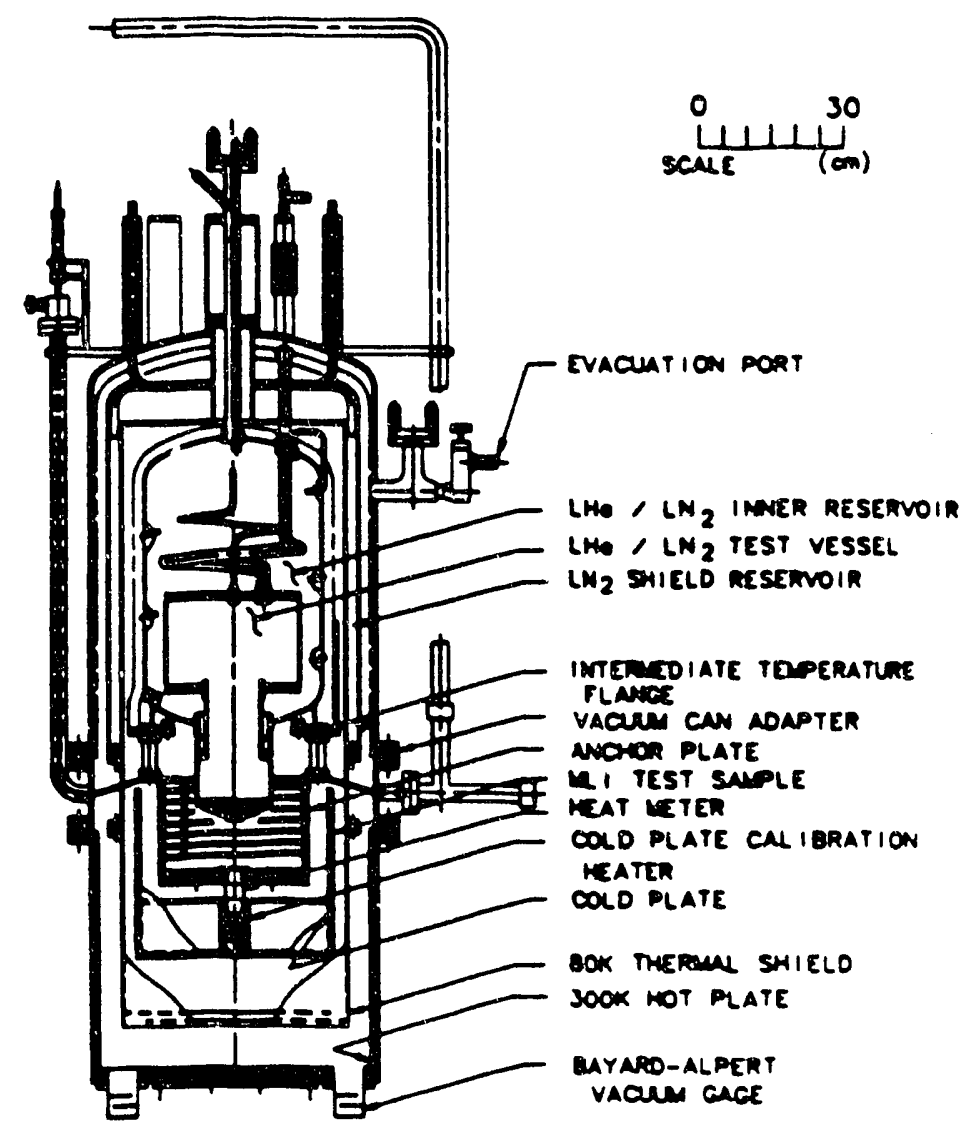

Figure 1. Heat Leak Test Facility for MUI measurements below $80 \mathrm{~K}$

\section{METHOD OF OPERATION}

Test samples are installed with the HLTF $180^{\circ}$ from the orientation shown in Figure 1. During initial pumpdown, heater tapes on the vacuum shell are powered to heat the apparatus and accelerate system outgassing. The system is evacuated to 1 micron, rolled into operating position, and then backfilled with dry nitrogen gas. The system is then evacuated a second time, the heater tapes turned off, and the vessels filled with cryogens. This evacuation process occurs over 3 working days. The first data points are taken under "good" insulating vacuum. Subsequent data points are taken with the cold plate beld near $20 \mathrm{~K}$ and the vacuum pump throttled to create "degraded" vacuum conditions. Finally, the vacuum is opened to the pump and the 20K data point repeated to ensure that no shift cocurred during degraded operation.

\section{MEASUREMENT RESULTS}

Table 1 outlines the systems evaluated during this program. The first measurement with aluminum tape on both boundary surfaces simulated a cryostat condition where no MLI was used. The second system modeled the MUI system configuration currently specified for the SSC $50 \mathrm{~mm}$ cryostat. This configuration consists of 10 reflective layers each separated by three spacer layers of spunbonded polyester mat. The reflective layers are $0.025 \mathrm{~mm}$ thick Mylar film aluminized on both sides to a nominal coating thickness of 600 angstromins. The tripte spacer layers serves to maintain low 
layer density, which is desirable at low temperatures where solid conduction is a dominant mode of beat transfer. The remaining systems were included to study the performance impact of blanket thickness, sewn seams, and aluminum coating thickness.

Table 1. Summary of insulation schemes evaluated sear $20 \mathrm{~K}$

\begin{tabular}{|c|c|c|c|c|c|c|c|}
\hline $\begin{array}{l}\text { Ten } \\
\text { No. }\end{array}$ & Sruem Dencotion & $\begin{array}{l}\text { Number of } \\
\text { Dan Lopers } \\
\text { (N) }\end{array}$ & $\begin{array}{l}\text { Laver } \\
\text { Haidita } \\
\text { (con) }\end{array}$ & $\begin{array}{l}\operatorname{lom}_{\text {Domidy }} \\
\text { Nusmil }\end{array}$ & $\underset{\operatorname{Pax}}{\max }$ & 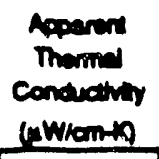 & $\begin{array}{l}\text { noulains } \\
\text { Veavm } \\
\text { nom }\end{array}$ \\
\hline$\pi$ & 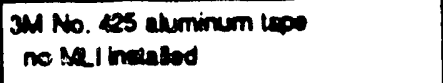 & - & - & - & 0.067 & - & $3.37 E-68$ \\
\hline $\mathbf{2}$ & 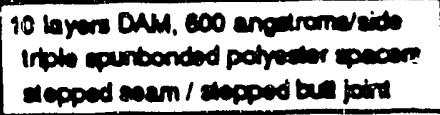 & 10 & 0.036 & 18.7 & 0.071 & 0.070 & $2.03 E-06$ \\
\hline $\mathbf{T}$ & 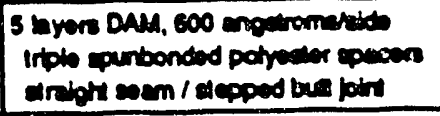 & $\mathbf{s}$ & 0.318 & 18.7 & 0.000 & 0.081 & $2.70 E-06$ \\
\hline T4 & 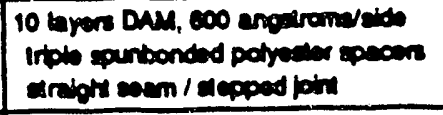 & 10 & 0.025 & 15.7 & 0.112 & 0.123 & J.34E- 06 \\
\hline T3 & 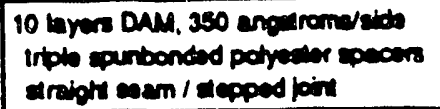 & 10 & 0.605 & 15.7 & 0.00 & 0.097 & $1.68 \pm 00$ \\
\hline
\end{tabular}

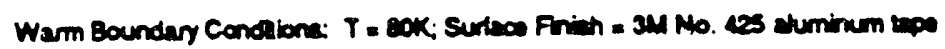

The data in Table 1 correspond to steady-state conditions at the noted vacuum levels. These points were selected for the table based on insulating vacuum levels that were closest to the cryostat design specification: limit radiant beat flux into the $20 \mathrm{~K}$ shield to $0.093 \mathrm{~W} / \mathrm{m}^{2}$ at $10^{-6}$ torr. The heat flux values may appear higher than those found elsewhere in the literature for MLI systems near $4 \mathrm{~K}^{6}$ This is due in part to the insulating vacuum at which this data was taken; gas conduction is a larger contributor at $10^{6}$ torr than at pressures of $10^{-7}$ torr and below.

Thermal performance of the three configurations (T2,T3, TA) that incorporated 600 angstrom DAM material is compared in Figures 2 and 3. At low pressures, performance is driven by the sewn seam geometry; the stepped seam geometry offered the lowest heat flux, and was the only MLI system below design budget. As the pressure increases, the impact of the seam becomes less significant while the effect of blanket thickness becomes a factor. These issues are discussed in subsequent sections.

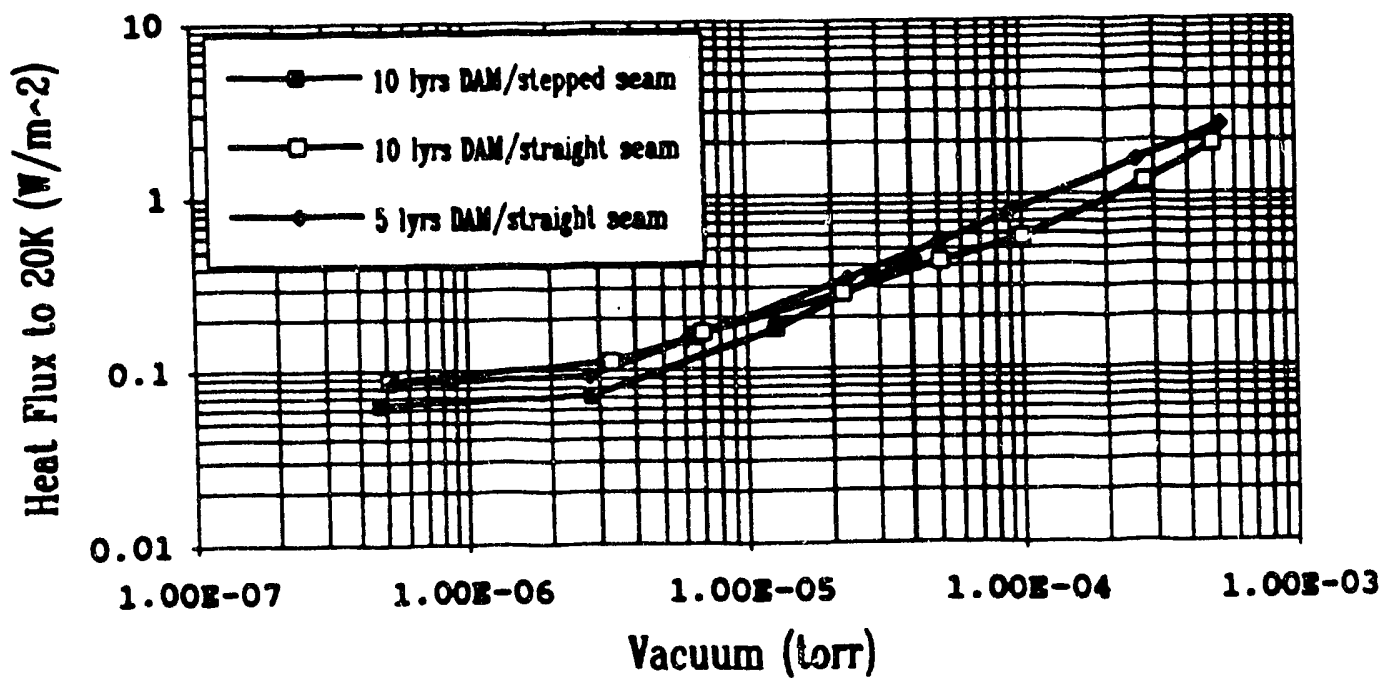

Figure 2 Heat fiux through MII systems near $20 \mathrm{~K}$ 


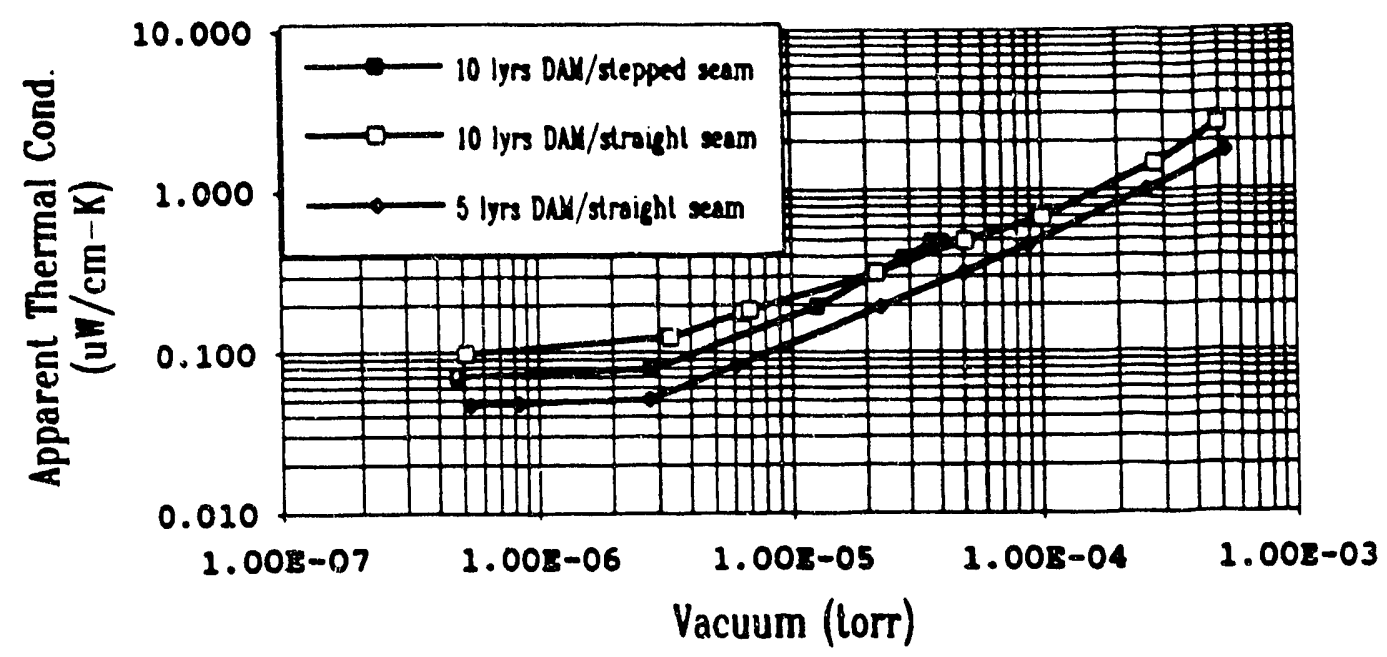

Figure 3. Apparent thermal conductivity of MUI systems near $20 \mathrm{~K}$

\section{Effect of Sewn Seam on Thermal Performance}

Sewn seams are used on all SSC MLI blankets to hold the many layers together during handling and cryostat installation. ${ }^{25}$ As radiant beat transfer falls off rapidly below $80 \mathrm{~K}$, solid conduction between MLI layers becomes a more significant contributor to overall heat transfer. Thus, to study whether the conduction ciontribution through a seam at $20 \mathrm{~K}$ has a significant impact on oyerall performance, 10-layer blankets with straight and stepped seams (T4 and T2) were evaluated and compared. The straight seam was sewn through all 10 layers with minimal stitch tension; the stepped seam was sewn through 5 layers, offser by $7.6 \mathrm{~cm}$, and then sewn through the remaining 5 layers. Measurement data shown in Figure 4 illustrates that the stepped seam blanket has a lower heat flux to $20 \mathrm{~K}$ at low pressure; the beat flux through the straight seam exceeds the design budget. As pressure increases, the performance of both blankets is driven by gas conduction with the seam contribution negligible by comparison. As a result of this comparison, the design of the SSC dipole cryostat 20K MLI blanket will continue to incorporate stepped sewn seams.

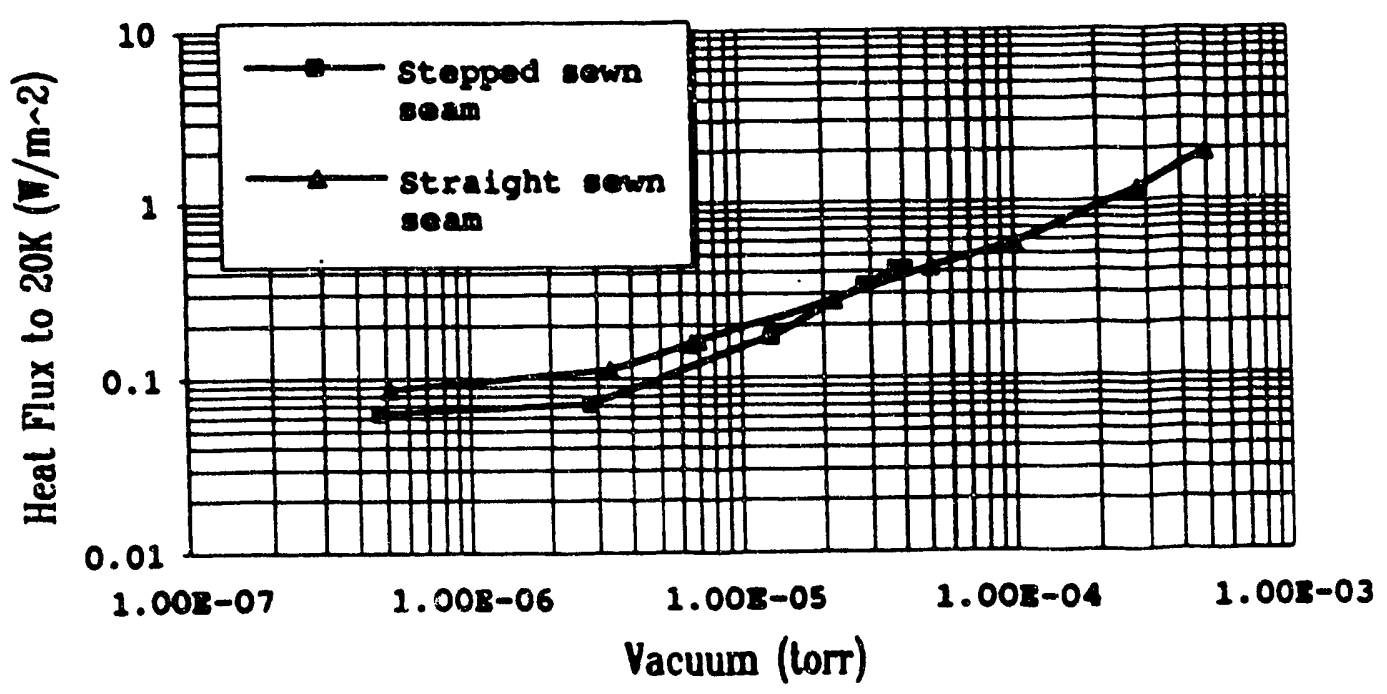

Figure 4. Effect of sewn seams on MaJ blanket performance 
Since radiation falls off rapidly below $80 \mathrm{~K}$, the number of reflective layers required to limit radiant beat transfer becomes less. In fact, if small heat fluxes are attainable between bare low emissivity surfaces, one might argue that the number of reflective layers is rather insignificant at these temperatures from a radiant heat transfer standpoint. The number of layers then become significant primarily during transient or upset conditions. To study this, a comparison was made between a 5-layer and 10 layer MLI blanket of like geometry and layer density (T3 and T4). The singular difference between test samples was overall thickness due to number of layers. Each blanket was comprised of DAM sheets with a coating thickness of 600 angstroms per side. Figure 5 shows that the performance of both blankets is comparable at low pressures, while beat flur through the 5-layer blanket is approximately $35 \%$ higher than through the 10-layer blanket as the pressure increases to $10^{-1}$ torr. This data is in agreement with the theory that reflective sheets serve as gas conduction barriers, and supports the continued use of 10-layer blankets for the cryostat $20 \mathrm{~K}$ MLI system.

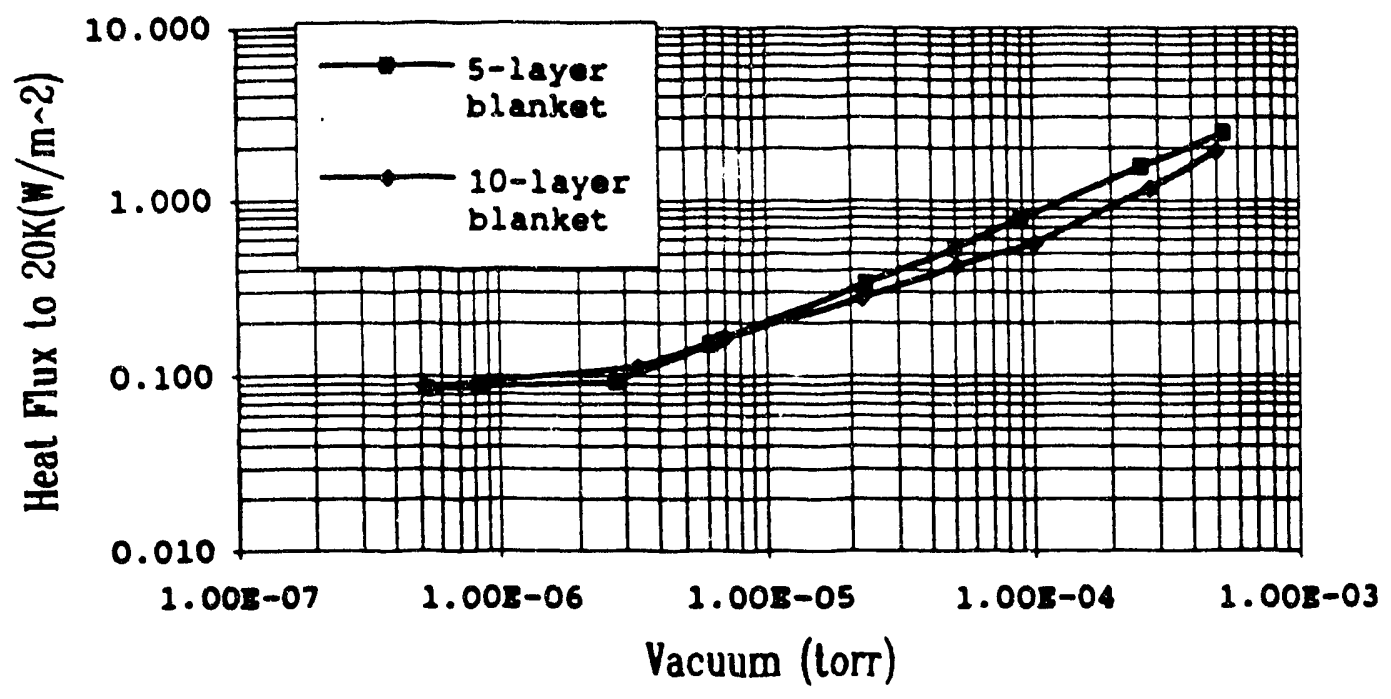

Figure S. Effect of blanket thickness on overall thermal performance

\section{Efrect of Aluminam Coating Thickeess on Thermal Performance}

It has been noted that the addition of MUI at temperatures near $4 \mathrm{~K}$ actually caused an increase in the rate of heat transfer. ${ }^{3}$ One explanation is based on the increased transmissivity of thin aluminum films at very low temperatures. ${ }^{3}$ Based on this theoretical prediction, the 20K MII system for the SSC cryostat is comprised of reflective sheets of DAM with aluminum coating thicknesses of 600 angstroms per side. By comparison, the $80 \mathrm{~K}$ MI system employs DAM sheets with aluminum coatings of 350 angstrom per side. To quantify the effect of aluminum coating thickens on MM performance at $20 \mathrm{~K}$, measurements were made on two blankets of like geometry (T4 and T5). Each blanket was comprised of 10 layers of DAM with three layers of spunbonded polyester mat separating each reflective pair. The blanket layers were fastened together with parallel straight sewn seams. The singular difference was that one blanket was comprised of 600 angstrom DAM; the second was comprised of 350 angstrom DAM. Figure 6 illustrates that an increase in aluminum coating thickness 
from 350 angstroms to 600 angstroms had no significant effect on overall thermal performance. As a result of this measurement, 350 angstrom DAM can be used in all MII systems in the SSC cryostat.

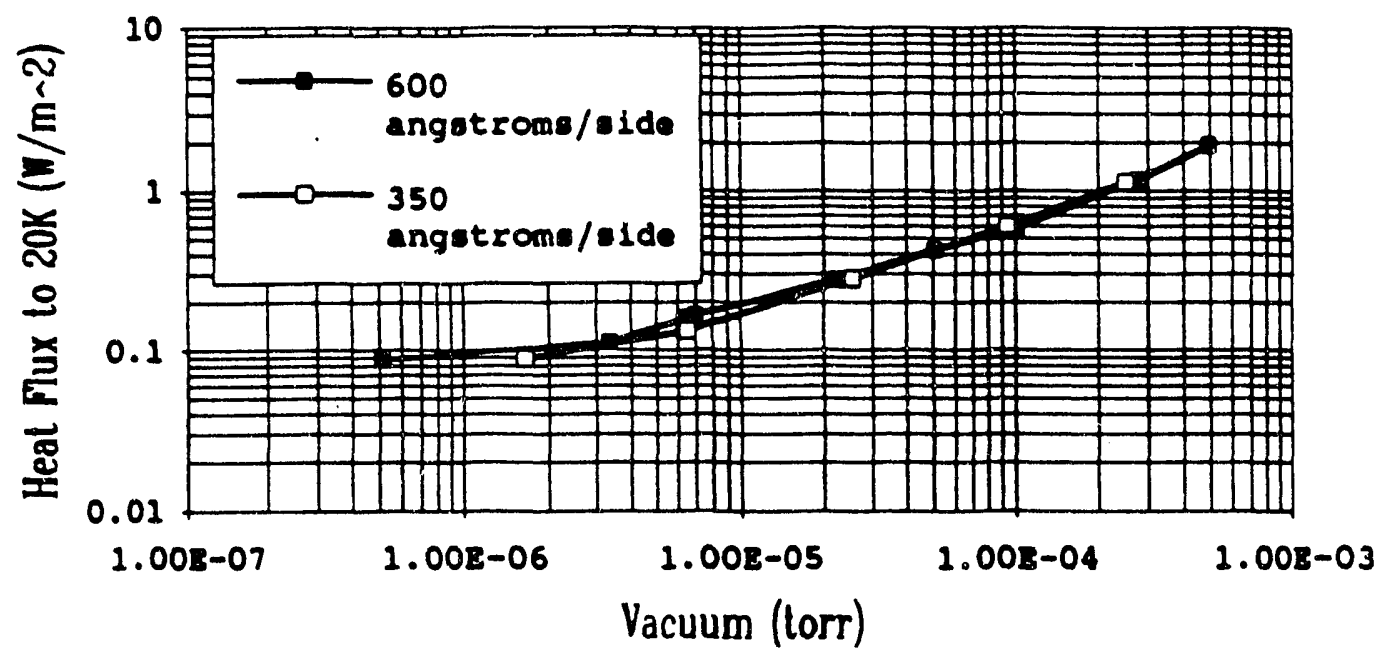

Figure 6. Effect of aluminum coating thickness on MLI performance

\section{CONCLUSION}

A number of insulation schemes have been evaluated between $80 \mathrm{~K}$ and $20 \mathrm{~K}$ to optimize the thermal insulation system for the SSC dipole cryostat Experimental results verify that the 10-layer MLI blanket currently specified for the SSC dipole cryostat 20K shield meets the design budget at an insulating vacuum of $10^{-6}$ torr. From the data, several other key points are noted:

- The region near $20 \mathrm{~K}$ is very sensitive to residual gas conduction. Insulating vacuum must be below $10^{-7}$ torr before the contribution of gas conduction to insulation performance becomes negligible.

- At vacuum levels near $10^{-6}$ torr, the number of reflective layers is not as important as bow the blanket is configured. Blankets fabricated with similar layer densities and fastening methods had the same performance even though one blanket had double the number of reflective layers.

- The number of reflective layers becomes important when insulating vacuum increases above $10^{-5}$ torr. The additional layers limit heat transfer by impeding residual gas conduction.

- Sewn seams impact the overall thermal performance of MUI blankets operating near 20K. The stepped sewn seam geometry specified for the SSC 20K MU system allows the many layers to be handled as a single component while still meeting the thermal design requirements. 
- The use of reflective films with 600 angstrom thick aluminum coatings offer no significant improvement in performance over similar systems comprised of films with 350 angstrom thick coatings. This will allow the use of reflective films aluminized with coating thicknesses of 350 angstroms in all SSC cryostat blankets without compromising system performance.

\section{ACKNOWLEDGEMENTS}

The authors wish to thank M. Ruschman and R. Kunzelman for their contributions in the development of the measurement facility and their assistance in the acquisition of this data. Gratitude is also expressed to D. Franks, R. Pletzer, A. Yucel, and others for countless discussions regarding the experimental results, and to M. McAshan, R. Coombes, and E.G. Pewitt for their support of this work

\section{REFERENCES}

1. T.H. Nicol, Design development for the $50 \mathrm{~mm}$ Superconducting Super Collider dipole cryostat, in: "Supercollider 3," Plenum Press, New York (1991), p. 1029.

2. J.D. Gonczy, W.N. Boroski, and R.C. Niemann, Thermal performance measurements of a 100 percent polyester MLI system for the Superconducting Super Collider: Part II, Laboratory Results (300K-80K), in: "Advances in Cryogenic Engineering," Vol. 35, Plenum Press, New York (1989), p.497.

3. E.M.W. Leung, et al., Techniques for reducing radiation heat transfer between 77K and 4.2K, in: "Advances in Cryogenic Engineering," Vol. 25, Plenum Press, New York (1980), p. 489.

4. W.N. Boroski, R.J. Kunzelman, M.K. Ruschman, and C.J. Schoo, Design and calibration of a test facility for MLJ thermal performance measurements below 80K, presented at the Cryogenic Engineering Conference, June 11-14, 1991, Huntsville, Alabama.

5. W.N. Boroski. T.H. Nicol, and C.J. Schoo, Design of the multilayer insulation system for the Superconducting Super Collider $50 \mathrm{~mm}$ dipole cryostat, in: "Supercollider 3," Plenum Press, New York (1991), p. 849.

6. I.E. Spradley, T.C. Nast, and DJ. Frank, Experimental studies of MLI systems at very low boundary temperatures, in: "Advances in Cryogenic Engineering," Vol. 35, Plenum Press, New York (1989), p. 477. 


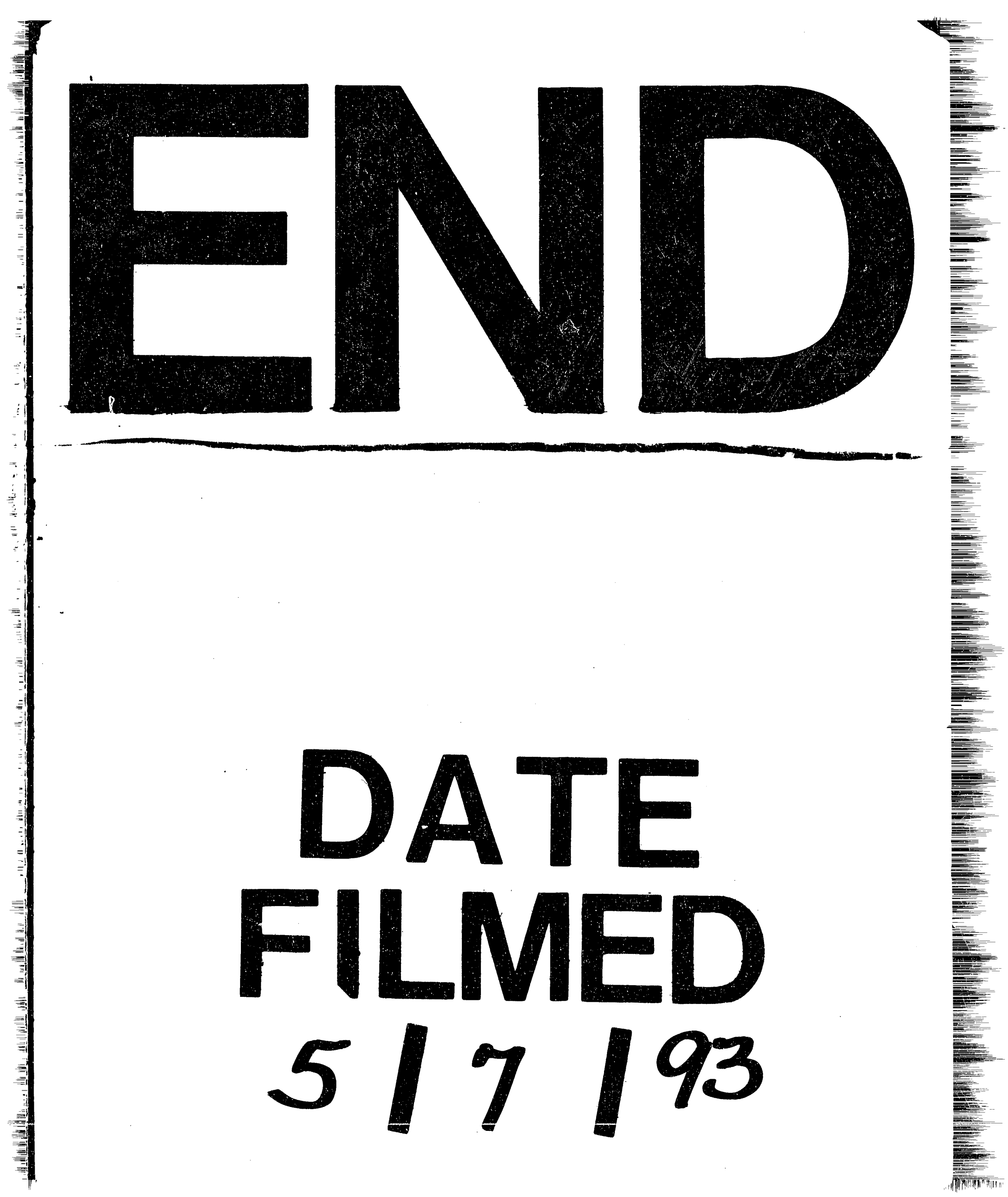


